\title{
Glossopharyngeal neuralgia treated by Gamma Knife radiosurgery: safety and efficacy through long-term follow-up
}

\author{
Benjamin Pommier, MD, MSc, ${ }^{1,2,3}$ Gustavo Touzet, MD, ${ }^{1}$ Christian Lucas, MD, PhD, ${ }^{1}$ \\ Maximilien Vermandel, PhD, ${ }^{4}$ Serge Blond, MD, PhD, ${ }^{1}$ and Nicolas Reyns, MD, $\mathrm{PhD}{ }^{1,4}$ \\ 1Department of Neurosurgery, CHRU Lille; ${ }^{4}$ INSERM U1189, Lille; ${ }^{2}$ Department of Neurosurgery, CHU Saint Etienne; and \\ ${ }^{3}$ INSERM U1028, Neuropain, Lyon, France
}

OBJECTIVE Glossopharyngeal neuralgia (GPN) is a rare and disabling condition. Just as for trigeminal neuralgia, Gamma Knife radiosurgery (GKRS) is increasingly proposed as a therapeutic option for GPN. The purpose of this study was to assess long-term safety and efficacy of GKRS for this indication.

METHODS From 2007 to 2015,9 patients ( 4 male and 5 female) underwent a total of 10 GKRS procedures. All of the
patients presented with GPN that was refractory to all medical treatment, and all had a long history of pain. One patient
had previously undergone surgical microvascular decompression. In 5 cases, a neurovascular conflict had been identi-
fied on MRI. For the GKRS procedure, the glossopharyngeal nerve was localized on MRI and CT under stereotactic
conditions. The target was located at the glossopharyngeal meatus of the jugular foramen. The dose administered to
the nerve was 80 Gy in 3 procedures and 90 Gy in the others. Follow-up was planned for 3,6 , and 12 months after the
procedure and annually thereafter.

RESULTS Eight patients experienced an improvement in their pain. The median length of time from GKRS to symptom improvement in this group was 7 weeks (range 2-12 months). At the first follow-up, 6 patients were pain-free (pain intensity scores of I-III, based on an adaptation of the Barrow Neurological Institute scoring system for trigeminal neuralgia), including 4 patients who were also medication-free (I). One patient had partial improvement (IV) and 2 patients had no change. The mean duration of follow-up was 46 months (range 10-90 months). At the last follow-up 6 patients remained pain-free (pain scores of I-III), including 4 patients who were pain free with no medication (I). No side effect was observed.

CONCLUSIONS Because of its safety and efficacy, GKRS appears to be a useful tool for treatment of GPN, including first-line treatment.

https://thejns.org/doi/abs/10.3171/2017.3.JNS162542

KEY WORDS vago-glossopharyngeal neuralgia; glossopharyngeal neuralgia; radiosurgery; Gamma Knife; stereotactic radiosurgery; pain

$\mathrm{E}$ SSENTIAL glossopharyngeal neuralgia (GPN) or vago-glossopharyngeal neuralgia (VGPN) is a rare condition manifesting as pain in the sensory territory of the ninth cranial nerve (CN IX). According to the criteria of the International Headache Society (IHS), it is described as a "severe, transient, stabbing, unilateral pain experienced in the ear, base of the tongue, tonsillar fossa and/or beneath the angle of the jaw."12 The pain is often provoked by swallowing, talking, or coughing. It can be accompanied by hypotension, syncope, and cardiac arrest. The evolution of the condition and the characteristics of the pain are comparable to what is seen in trigeminal neuralgia, with remitting and relapsing phases. Because of the rarity of GPN, data are sparse; however, its overall incidence seems much smaller than that of trigeminal neuralgia: $0.2-0.7$ cases per 100,000 persons per year and $0.2 \%-1.3 \%$ of orofacial pain syndromes. ${ }^{2,14,32}$ In the idiopathic type of GPN, its physiopathology is compared with trigeminal neuralgia and is often attributed to neurovascular conflict. ${ }^{2,7,37}$ The condition may also be due to tumors either in the cerebellopontine angle or in extracranial locations such as the oropharynx.1,8

The medical treatment of GPN is similar to that of trigeminal neuralgia and is mainly based on carbamaze-

ABBREVIATIONS BNI = Barrow Neurological Institute; $C N$ = cranial nerve; FIESTA = fast imaging employing steady-state acquisition; GKRS = Gamma Knife radiosurgery; GPN = glossopharyngeal neuralgia; IHS = International Headache Society; MVD = microvascular decompression; VGPN = vago-glossopharyngeal neuralgia. SUBMITTED November 24, 2016. ACCEPTED March 23, 2017.

INCLUDE WHEN CITING Published online June 16, 2017; DOI: 10.3171/2017.3.JNS162542. 

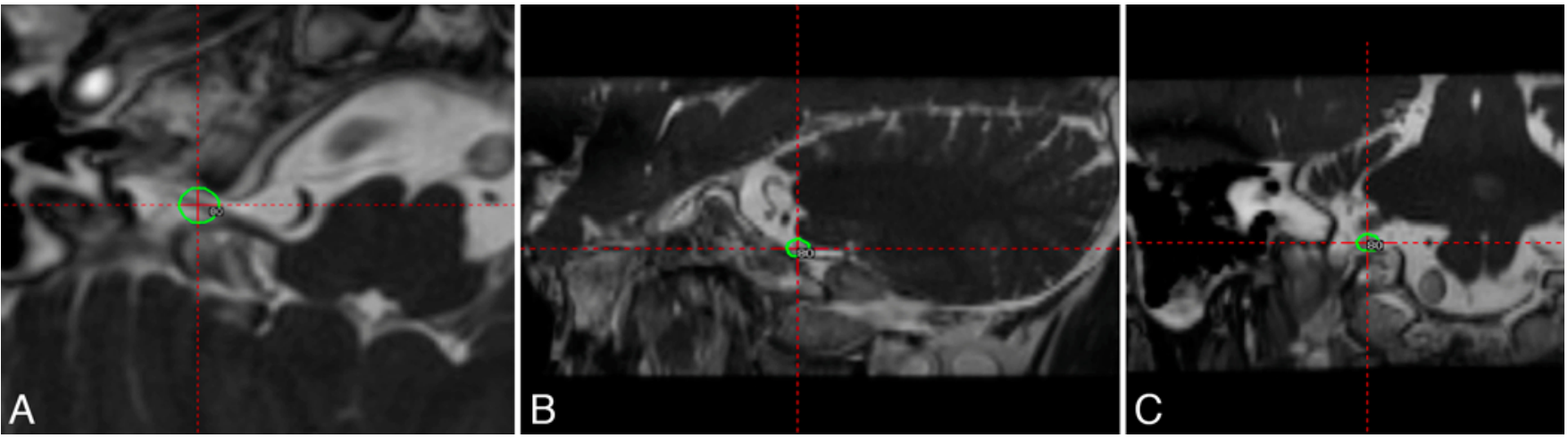

FIG. 1. FIESTA MR images fused with CT from Leksell GammaPlan software displaying axial (A), sagittal (B), and coronal (C) plans. The green outline represents the $80 \%$ isodose line. Figure is available in color online only.

pine. Other antiepileptic drugs, such as phenytoin, oxcarbazepine, and gabapentin, or amitriptyline may also be used. ${ }^{3,6,31}$ Refractory neuralgia or treatment intolerance can lead to surgical treatment. As for trigeminal neuralgia, surgical treatment mainly consists of MV or rhizotomy of the glossopharyngeal nerve. ${ }^{2}$ Surgery provides high rates of pain relief (up to $80 \%-90 \%$ ) and sustained results, especially when microvascular decompression (MVD) is performed. ${ }^{2,29}$ However, surgery also is associated with substantial risk of damage to cranial nerves. Permanent cranial nerve damage occurs in $5.5 \%$ of patients treated with MVD on average and up to $19.1 \%$ of those treated with rhizotomy. ${ }^{2,29}$ Therefore, in the manner of trigeminal neuralgia treatment, Gamma Knife radiosurgery (GKRS) has been proposed as a useful, efficient, and safe procedure for the treatment of GPN. ${ }^{24,36,41}$ To date, only small retrospective case-series have been described, reporting on a total of 27 patients treated. The largest series report the consecutive results of 7 treated patients.

We present here the results of 10 procedures in 9 patients treated with GKRS for refractory GPN.

\section{Methods}

\section{Patient Characteristics}

From 2008 to 2015,9 patients (4 male and 5 female) were treated with GKRS for refractory GPN at Lille University Hospital. Their median age was 54 years (range 36-80 years). The median duration of pain was 6 years (range 2-20 years). The pain was right-sided in 5 cases and left-sided in 4 cases. Eight patients presented with persistent pain despite maximal medical treatment, and 6 patients presented with side effects of carbamazepine. All 9 patients satisfied the IHS criteria for GPN. Five patients had a neurovascular conflict demonstrated on MRI. One patient had previously undergone microvascular decompression (MVD) for VGPN. All 9 patients underwent a consultation with and fibroscopic examination by an ENT specialist to exclude secondary GPN, especially GPN due to a head or neck cancer.

\section{Radiosurgical Procedure}

GKRS was performed using a Leksell stereotactic frame (Elekta Instruments $\mathrm{AB}$ ) placed under local anesthesia supplemented with an inhaled anesthetic agent.
Patients then underwent MRI and CT. MRI sequences were $3 \mathrm{D}$ fast imaging employing steady-state acquisition (FIESTA, General Electrics) or constructive interference in steady state (CISS, Siemens) and 3D magnetizationprepared rapid acquisition gradient echo (MPRAGE) with gadolinium. These sequences were acquired in stereotactic conditions (with the frame on), as described previously for the treatment of vestibular schwannoma, ${ }^{10,11}$ and could be fused with a CT bone window scan to obtain the most accurate modality.

The Leksell GammaPlan software (v10.1.1, Elekta Instrument $\mathrm{AB}$ ) was used to coregister images and establish the radiosurgical planning.

As suggested in the literature, ${ }^{24,26,39}$ we chose as a target the distal part of the glossopharyngeal nerve at the level of the glossopharyngeal meatus of the jugular foramen (Fig. 1).

A maximum dose of 80 or 90 Gy was administered with a 4-mm collimator, taking particular care with respect to the dose delivered to the brainstem. For each patient, we monitored the maximum dose delivered to a 10$\mathrm{mm}^{3}$ volume of the brainstem, the maximal dose delivered to the brainstem, and the mean dose delivered to the nerve.

Patients left the hospital the day following the radiosurgical procedure. They were followed up by clinical examination 3 months, 6 months, and 1 year after the procedure. Subsequent follow-up was scheduled annually thereafter (including follow-up by telephone interview). A large majority of these patients were followed by the treating neurosurgeon in our center but 2 of them were followed by the referring neurosurgeon because of their geographical location. After the GKRS procedure, patients were told to continue their medications until they felt an improvement. In case of improvement, they were told to progressively decrease their medications. They were assessed for pain status, medication use, and potential side effects (involving swallowing, choking, or vocal changes).

Pain relief was assessed using the widespread Barrow Neurological Institute (BNI) pain intensity scoring system $^{30}$ adapted to glossopharyngeal neuralgia: I, no glossopharyngeal pain with no medication; II, occasional pain that does not require medication; IIIa, no pain with continued medication; IIIb, persistent pain controlled by medication; IV, some pain not adequately controlled by medication; and $\mathrm{V}$, severe pain with no relief. 
TABLE 1. Demographical, clinical, and surgical outcome data for the 9 patients who underwent GKRS treatment

\begin{tabular}{lcccccccccc}
\hline $\begin{array}{c}\text { Case } \\
\text { No. }\end{array}$ & Sex & $\begin{array}{c}\text { Age } \\
\text { (yrs) }\end{array}$ & $\begin{array}{c}\text { Pain } \\
\text { Side }\end{array}$ & $\begin{array}{c}\text { Pain Duration } \\
\text { (yrs) }\end{array}$ & $\begin{array}{c}\text { Vascular } \\
\text { Conflict on MRI }\end{array}$ & $\begin{array}{c}\text { Max Dose } \\
(\text { Gy) }\end{array}$ & $\begin{array}{c}\text { Duration of } \\
\text { FU (mos) }\end{array}$ & $\begin{array}{c}\text { Relief } \\
\text { Onset (wks) }\end{array}$ & $\begin{array}{c}\text { 6-Mo BNI } \\
\text { Score }\end{array}$ & $\begin{array}{c}\text { Last FU } \\
\text { Score } \\
\text { BNI }\end{array}$ \\
\hline 1 & F & 59 & Rt & 20 & Yes & 80 & 90 & 8 & I & IIla \\
\hline 2 & M & 43 & Rt & 4 & No & 80 & 84 & 2 & IIla & I \\
\hline 3 & F & 64 & Rt & 14 & Yes & 80 & 80 & 8 & IV & NA \\
\hline 4 & M & 80 & Lt & 8 & No & 90 & 32 & 8 & IV & NA \\
\hline 5 & M & 62 & Lt & 2 & Yes & 90 & 22 & NA & V & V \\
\hline 6 & F & 36 & Rt & 6 & No & 90 & 16 & 8 & I & I \\
\hline 7 & M & 49 & Lt & 5 & Yes & 90 & 10 & 6 & I & I \\
\hline 8 & F & 54 & Rt & 3 & No & 90 & 10 & 6 & I & I \\
\hline 9 & F & 51 & Lt & 4 & Yes & 90 & 67 & 12 & IIIa & NA \\
\hline $9 b^{*}$ & F & 54 & Lt & 7 & Yes & 90 & 31 & 3 & IIIa & IIIa \\
\hline
\end{tabular}

BNI Score = BNI pain intensity score (adapted for GPN); FU = follow-up; NA = not available.

* The patient in Case 9 underwent repeat GKRS (once at age 51 and once at age 54).

\section{Statistical Analysis}

All the statistical analyses were performed using $\mathrm{R}$ software (version 3.1.2, R Foundation for Statistical Computing). The survival package in $\mathrm{R}$ was used for the survival analysis. For the evaluation of outcomes, the time to event was estimated using the Kaplan-Meier method. Kaplan-Meier curves were used to graphically represent the survival curve.

Univariate analysis was then performed to identify the predictive factors among the collected variables. For qualitative variables (neurovascular conflict, prior MVD, and response to medical treatment), the Fisher exact test was used. For quantitative variables (previous pain duration, age, maximum dose) a Spearman correlation test was performed. The $\mathrm{p}$ value was corrected with the Bonferroni method. Corrected $\mathrm{p}$ values $<0.05$ were considered as significant.

\section{Results}

The follow-up period ranged from 10 to 90 months (mean 46 months). At the 6-month follow-up evaluations, 6 patients were pain free (pain intensity scores of I-III), including 4 who were pain free without medication (score of I). Two patients were classified as having had partial improvement (score of IV), and in 1 case the patient's pain intensity remained unchanged (score of $\mathrm{V}$ ). The patient in Case 9 was pain free for 3 years and then presented with a recurrence requiring a second GKRS procedure (Case 9b). The results are summarized in Table 1.

At the last follow-up, 4 patients remained pain free without medication (score of I), 2 patients remained pain free with medication (IIIa), and 1 patient's pain remained unchanged (V). Despite extensive otorhinolaryngological investigations before radiosurgery, 2 patients (Cases 3 and 4) were discovered to have cavum tumors that were subsequently resected. The patient in Case 4 did not obtain pain relief from tumor surgery, whereas the patient Case 3 became pain free after tumor surgery.

Considering only the 7 patients who were not found to be harboring a tumor, the probability of achieving free- dom from pain associated with GPN was $88 \%$ (95\% CI $39-98 \%$ ) for the period from 6 to 35 months after GKRS and 58\% (95\% CI 77-89\%) from 36 months on. The probability of being pain free without medications was $62 \%$ (95\% CI 23\%-86\%) for 6-35 months after GKRS and $31 \%(95 \%$ CI $1.5 \%-72 \%)$ for 36 months and later. Results are summarized in Fig. 2.

No predictive factor for success or failure was identified (Table 2). A neurovascular conflict was clearly identified in 5 of 9 patients.

The median maximum dose delivered to a $10-\mathrm{mm}^{3}$ volume of the brainstem was 2.59 Gy (range 1.45-9.5). The median maximum dose delivered to the brainstem was 3.35 Gy (range 1.8-13.5). The median mean dose delivered to the nerve was 32.7 Gy (range 18.7-42.8). Dosimetric data are detailed in Table 3.

We did not observe any complications after GKRS treatment in these patients-in particular, we observed no motor impairment or worsening of sensory functions of the glossopharyngeal nerve.

\section{Discussion}

Glossopharyngeal (or vago-glossopharyngeal) neuralgia (GPN or VGPN) appears broadly similar to trigeminal neuralgia. Nevertheless its incidence is much lower (a magnitude of difference of up to 100-fold), varying around $0.7 / 100,000$ patients per year. ${ }^{14}$ Sicard and Robineau reported this entity in 1920, and it was named "glossopharyngeal neuralgia" in 1921 by Harris. ${ }^{9}$ As for trigeminal neuralgia, the standard surgical treatments for GPN are rhizotomy, microvascular decompression (MVD), and percutaneous radiofrequency thermocoagulation. In 1927, Dandy first described the surgical treatment of VGPN by intracranial section of the glossopharyngeal nerve. ${ }^{2}$ In 1981, Rushton et al. ${ }^{32}$ reported 217 cases treated at the Mayo Clinic, including 129 that were treated surgically. The surgical procedure was rhizotomy in a large majority. In 1977, Laha and Janetta, ${ }^{17}$ based on the treatment of trigeminal neuralgia, proposed the use of MVD for the treatment of GPN. MVD 

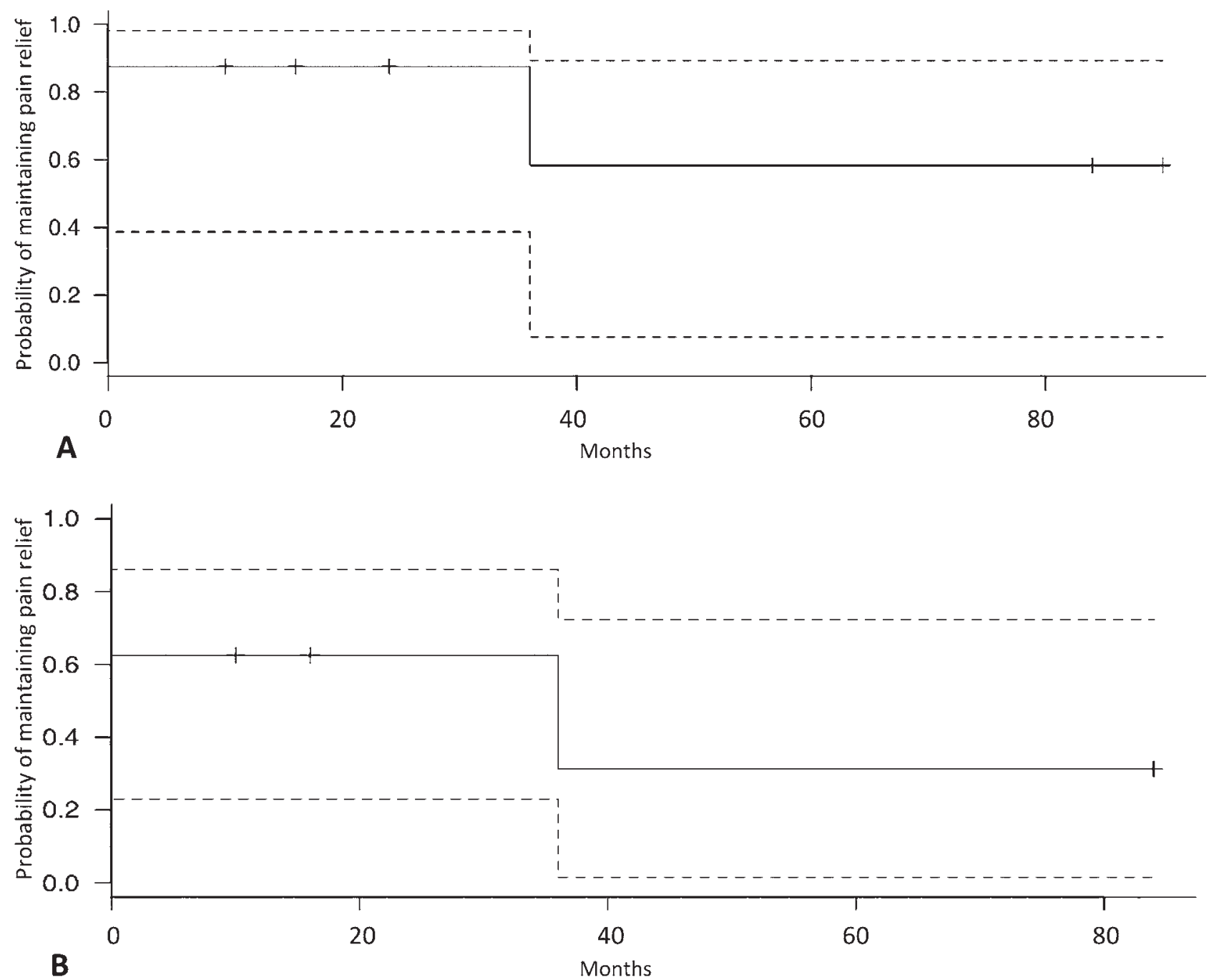

FIG. 2. Actuarial probability of maintaining pain relief with $(\mathbf{A})$ and without (B) medication in our cohort. (The broken lines indicate the upper and lower bounds of the 95\% confidence interval.) The actuarial probability of maintaining pain relief from 6 to 35 months was $88 \%$; the probability of maintaining pain relief after 36 months was $58 \%$. The actuarial probability of maintaining pain relief without medication from 6 to 35 months was $62 \%$, and the probability of maintaining pain relief without medication after 36 months was $31 \%$.

has been supported by a few large North American cohort studies. ${ }^{5,15,25,33}$ At the end of the 1970 s, Lazorthes and Verdie $^{18,19}$ also proposed percutaneous thermocoagulation of Andersch's ganglion as a therapeutic option in VGPN.

All of these surgical treatments appear to be effective, with rates of excellent relief varying from $76 \%$ to $100 \%$, depending on the series and including long-term followup. The main drawbacks of these techniques are the rates of associated complications.

Because of their lesioning processes, intracranial glossopharyngeal rhizotomy or vago-glossopharyngeal rhizotomy and percutaneous radiofrequency thermocoagulation entail a risk of sensory deficits and complications such as dysphagia and hoarseness. Intracranial rhizotomy was one of the first proposed treatments. There are few series describing these techniques, ${ }^{21,32}$ a recent large-cohort study involving 103 patients treated by a trained team ${ }^{21}$ reported an overall rate of immediate and surgical complications (such as CSF leakage and wound healing problems) of
$5.8 \%$ and a $25.3 \%$ rate of permanent complications (mainly swallowing problems). Percutaneous radiofrequency thermocoagulation has been reported in a few case series, but it has many major drawbacks: it is technically far more difficult than gasserian thermocoagulation because of the nerve location and the high risk of injury to adjacent structures (mainly the jugular vein). Moreover, it is associated with many side effects (diminished gag reflex, dysphagia, and vocal cord paralysis). For these reasons, some authors ${ }^{2}$ recommend this procedure for patients with GPN secondary to neoplastic disease or very weak patients who are not able to tolerate an open surgery.

With respect to MVD, the 5\% mortality rate reported for early cohorts ${ }^{2,32}$ does not seem current anymore. Nevertheless, temporary deficits such as dysphagia, hoarseness, or cough are described in $10 \%$ to $34 \%$ of patients, and definitive deficits in $0 \%$ to $17 \%$ of patients. ${ }^{15,25,29,33,34}$

Like trigeminal neuralgia, GPN often occurs in elderly patients in whom surgery and anesthesia can bring many 
TABLE 2. Univariate analysis of potential predictive factors for treatment success or failure

\begin{tabular}{lc}
\hline \multicolumn{1}{c}{ Variable } & $p$ Value* \\
\hline Neurovascular conflict & $>0.99$ \\
\hline Medical treatment efficacy & 0.72 \\
\hline Previous MVD & $>0.99$ \\
\hline Previous pain duration & $>0.99$ \\
\hline Age & $>0.99$ \\
\hline Max dose & $>0.99$ \\
\hline
\end{tabular}

* Corrected with the Bonferroni method.

risks. That is why GKRS has been proposed, initially as a second-line treatment, for trigeminal neuralgia, and is becoming more and more frequently used, including as a first-line treatment. ${ }^{27}$ Even if MVD seems to provide better long-term pain-relief, GKRS pain-relief rates are quite close, with substantially lower rates of adverse events. $4,16,27,28$ This is the reason why we decided to recommend GKRS first and to propose MVD in cases of GKRS treatment failure. This kind of attitude is already proposed by the Marseille team for trigeminal neuralgia, as they have shown that poorer pain relief is provided by GKRS in patients who have previously undergone MVD. ${ }^{38}$ This approach is probably the most meaningful in cases involving older patients presenting comorbidities.

Following the example of trigeminal neuralgia treatment, GKRS was first proposed for GPN (VPGN) in 2005. To our knowledge, 27 cases have since been reported, with various targets, dosimetry, and follow-up (Table 4). ${ }^{13,20,22,24,26,35,36,39-41}$ The most frequent targets were the cisternal part of the glossopharyngeal nerve and its distal end, at the level of glossopharyngeal meatus. In the 27 reported cases, 6 patients (22\%) were treated using the cisternal part of the nerve and $21(78 \%)$ using the meatus. The dose used varied from 60 to 90 Gy (mean $79.3 \mathrm{~Gy}$ ). In all 4 cases in which a dose less than 75 Gy was used, the treatment failed. ${ }^{20,41}$ As suggested by the Marseille team experience, ${ }^{20}$ the best results are obtained using the "meatus target" with a dose of at least $75 \mathrm{~Gy}$.

Based on these data, we treated our patients using the meatus target with an initial maximum dose of 80 Gy (Cases 1-3) and then a maximum dose of 90 Gy (Cases 4-9b). The maximum dose was increased following the parallel with trigeminal neuralgia. A maximum dose of 90 Gy is known to provide better clinical results in safe conditions. ${ }^{23}$ Moreover, because of the anatomy of the brainstem, it is easier and probably safer to provide $90 \mathrm{~Gy}$ to the glossopharyngeal nerve target than to the trigeminal nerve one. Nevertheless, we did not find any statistically significant difference between these 2 maximum doses $(80$ and $90 \mathrm{~Gy}$ ). The absence of side effects in our series is in favor of the use of the 90-Gy dose.

As noted in the 27 other cases reported in the literature, we did not observe any adverse events. A total experience of 36 cases is not enough to warrant a definitive statement on the safety of the procedure, but the GPN target is often further from the brainstem than the target in patients with trigeminal neuralgia, and this may be a reason for the lack of reported complications.

Our follow-up remains limited, with 2 patients having
TABLE 3. Dosimetric data by case

\begin{tabular}{cccccc}
\hline \multirow{2}{*}{$\begin{array}{c}\text { Case } \\
\text { No. }\end{array}$} & $\begin{array}{c}\text { Max Dose } 10 \mathrm{~mm}^{3} \\
\text { Brainstem }(G y)^{*}\end{array}$ & $\begin{array}{c}\text { Max Dose } \\
\text { Brainstem (Gy) }\end{array}$ & \multicolumn{3}{c}{ Dose to CN IX (Gy) $\neq$} \\
\cline { 4 - 6 } & 1.92 & 2.4 & 80.4 & 30.4 & 1.8 \\
\hline 1 & 2.32 & 3.4 & 80.4 & 21.3 & 1.5 \\
\hline 2 & 4.01 & 5.7 & 81.2 & 37 & 3.6 \\
\hline 3 & 3.55 & 4.7 & 90.1 & 36.9 & 3.7 \\
\hline 4 & 1.9 & 2.2 & 90.9 & 26.5 & 0.9 \\
\hline 5 & 9.5 & 13.5 & 90.1 & 42.8 & 6.2 \\
\hline 6 & 1.45 & 1.8 & 90.1 & 18.7 & 1.9 \\
\hline 7 & 4.15 & 6.1 & 90 & 42.8 & 3.2 \\
\hline 8 & 2.06 & 2.4 & 90.1 & 30.2 & 2.2 \\
\hline 9 & 2.86 & 3.3 & 89.9 & 35 & 2.6 \\
\hline $9 b$ & & & & & \\
\hline
\end{tabular}

$\mathrm{CN}=$ cranial nerve Min $=$ minimum.

* Maximum dose delivered to a $10-\mathrm{mm}^{3}$ volume of the brainstem.

$\dagger$ Maximum dose delivered to the brainstem.

$\ddagger$ Maximum, mean, and minimum doses delivered to the glossopharyngeal nerve (CN IX).

less than 12 months of follow-up as of this writing, but our mean follow-up (46 months) makes our case series the one with the longest follow-up to date. As of this writing, only 1 recurrence was noticed in a patient for whom GKRS had been successful (Case 9, Table 1). That patient underwent a second GKRS, which has been successful so far (3 years' follow-up).

An improvement was often noticed soon (within days of treatment), but the maximum pain relief was noticed at a median of 8 weeks after GKRS. If we consider the 6-month results for the 10 treatments in our series (including data for Case 9 and Case $9 \mathrm{~b}$ in the analysis), $44 \%$ resulted in the patients being pain free without medications at 6 months after treatment, $70 \%$ resulted in the patients being pain free, and $30 \%$ resulted in only slight improvement or none. Analyzing the data for the 6- to 36-month posttreatment period on a per patient basis and including all 9 patients (i.e., including the 2 patients who subsequently presented with head and neck cancer), we also obtain a rate of $44 \%$ for pain freedom without medication; but if we consider only the patients who presented with typical GPN, the results are completely different $-62 \%$ of patients would then be pain free without medication and $88 \%$ of patients would be pain free (with or without medication).

Our results appear to be consistent with the 27 cases previously reported in the literature (Table 4). At the first follow-up, $81 \%(\mathrm{n}=22)$ of the patients in the previously reported cases were pain free, and $74 \%(n=20)$ were pain free without medication. With a mean follow-up of 24.6 months (range 6-83 months), there were 3 recurrences, which increased the failure ratio to $30 \%$.

Interestingly, of the 23 previously reported patients treated with at least 75 Gy and the 9 we present here, only 2 relapsed, even with long-term follow-up. The recurrence rate seems low, especially when compared with recurrence rates reported for trigeminal neuralgia. ${ }^{16,27}$ Nevertheless, the small size of this sample and its heterogeneity prevent us from drawing firm conclusions.

Regarding our 3 patients who experienced little or no 
TABLE 4. Reported cases of patients suffering from essential GPN treated with GKRS

\begin{tabular}{|c|c|c|c|c|c|c|}
\hline Authors \& Year & Target* & $\begin{array}{l}\text { Max Dose } \\
\text { (Gy) }\end{array}$ & Initial Outcome & $\begin{array}{c}\mathrm{FU} \\
\text { (mos) }\end{array}$ & $\begin{array}{c}\text { Pain } \\
\text { Recurrence }\end{array}$ & $\begin{array}{c}\text { Adverse } \\
\text { Effects }\end{array}$ \\
\hline Héroux \& Mathieu, 2015 & GPM & 80 & 1 (pain free w/o med) & 44 & No & No \\
\hline \multirow[t]{3}{*}{ Xiong et al., 2015} & Cistern & 80 & 1 (pain free w/o med) & 28 & No & No \\
\hline & Cistern & 80 & 1 (pain free w/o med) & 25 & No & No \\
\hline & Cistern & 86 & 1 (pain free w/o med) & 23 & No & No \\
\hline \multirow[t]{5}{*}{ Martínez-Álvarez et al., 2014} & GPM & 80 & 3 (pain free w/ med) & 83 & No & No \\
\hline & GPM & 90 & 1 (pain free w/o med) & 71 & No & No \\
\hline & GPM & 90 & 1 (pain free w/o med) & 31 & No & No \\
\hline & GPM & 90 & 1 (pain free w/o med) & 19 & No & No \\
\hline & GPM & 90 & 1 (pain free w/ med) & 14 & No & No \\
\hline O'Connor \& Bidiwala, 2013 & GPM & 80 & 1 (pain free w/o med) & 16 & No & No \\
\hline Stanic et al., 2012 & GPM & 80 & 4 (persistent pain controlled by med) & 12 & NA & No \\
\hline \multirow[t]{5}{*}{ Pollock \& Boes, 2011} & GPM & 80 & 1 (pain free w/o med) & 19 & No & No \\
\hline & GPM & 80 & 1 (pain free w/o med) & 16 & No & No \\
\hline & GPM & 80 & 1 (pain free w/o med) & 13 & No & No \\
\hline & GPM & 80 & 5 (unchanged) & NA & NA & No \\
\hline & GPM & 80 & 5 (unchanged) & NA & NA & No \\
\hline \multirow[t]{7}{*}{ Lévêque et al., 2011} & GPM & 70 & 1 (pain free w/o med) & 10 & Yes (7 mos after 2 nd Tx) & No \\
\hline & Cistern & 70 & 4 (some pain not adequately controlled by med) & 24 & NA & No \\
\hline & Cistern & 70 & 4 (some pain not adequately controlled by med) & 24 & NA & No \\
\hline & GPM & 75 & 1 (pain free w/o med) & 32 & No & No \\
\hline & GPM & 80 & 1 (pain free w/o med) & 13 & No & No \\
\hline & GPM & 80 & 1 (pain free w/o med) & 10 & No & No \\
\hline & GPM & 80 & 1 (pain free w/o med) & 8 & No & No \\
\hline Williams et al., 2010 & GPM & 75 & 1 (pain free w/o med) & 11 & No & No \\
\hline \multirow[t]{2}{*}{ Yomo et al., 2009} & GPM & 60 & 3 (pain free w/ med) & 50 & Yes (2 mos) & No \\
\hline & GPM & 75 & 1 (pain free w/o med) & 12 & No & No \\
\hline Stieber et al., 2005 & Cistern & 80 & 1 (pain free w/o med) & 6 & Yes (6 mos) & No \\
\hline
\end{tabular}

GPM = glossopharyngeal meatus; med = medication; $\mathrm{Tx}=$ treatment.

* Cisternal part of the glossopharyngeal nerve (indicated here by cistern) or its distal end, at the level of glossopharyngeal meatus.

improvement, the first (Case 5) presented some atypical pain features (slight pain background). Nonetheless, because of the pain intensity and resistance to treatment (including MVD), we decided to try to treat his condition with GKRS. The patient did not report any pain relief, and 1 year later, he developed atypical semiological characteristics (pain irradiation out of the glossopharyngeal territory) that led us to reconsider the GPN diagnosis. No other investigations led to a secondary GPN.

The 2 other patients in this group were discovered to have neoplastic lesions much later, despite an initial exploration to exclude secondary GPN. The patient in Case 3 was found to have a head and neck cancer of unknown histology 5 years after GKRS and 19 years after the beginning of her pain (the patient was operated on far from our center). Tumor resection totally relieved the pain. The patient in Case 4 was found to have a rare arytenoid cartilage atypical neuroendocrine tumor. This lesion was found 2 years after his GKRS procedure and 10 years after the beginning of his pain. The patient underwent a total endoscopic resection of the tumor. The pain was partially relieved for a few months and then recurred.
These 2 patients illustrate the problem of the diagnosis of GPN. Because of its rarity and its semiological characteristics, the diagnosis of essential GPN can be very difficult. A strict preoperative head and neck cancer screening should be systematically performed but can be insufficient. Finally, these 2 patients probably did not suffer from typical GPN, and for that reason they were excluded from the statistical analysis.

As previously shown by Pollock and Boes, ${ }^{26}$ inefficacy should be first assigned to an incorrect diagnosis. They also presented 2 treatment failures: in one case, the patient had a tumor, and in the other, the patient was ultimately found to have orofacial pain of undetermined cause.

We could highlight another potential failure factor, which is the difficulty of accurately localizing the glossopharyngeal nerve, especially in its meatus portion. Nevertheless, it is important to stress that CT scan fused with 3D balance gradient echo MRI can be of help to delineate the target as it provides a good imaging of the bones and nerve structures. The coregistration of these imaging modalities allows limitation of MRI-induced distortion. This appears as a prominent point in the case of such a small target. 


\section{Conclusions}

As shown in review articles, ${ }^{2,29}$ GKRS is still not considered a primary treatment in the management of GPN, and the number of treated patients and the proof level remain low. Nevertheless, in the light of our data, added to the existing data, it appears as a safe and, effective treatment option for sustained relief of GPN. All of these points should lead to consideration of GKRS as an option for first-line treatment of essential GPN, especially in the elderly. It should be reserved for patients with typical primary GPN diagnosed after exhaustive exploration to rule out secondary GPN. In our opinion, a maximum dose of 90 Gy should be administered to the meatus target. Furthermore, the patients should be strictly followed at least at 3,6, and 12 months after treatment to look for complications, even if they seem rare.

\section{References}

1. Carrat X, François JM, Houliat T, Bertrand B, Devars F, Traissac L: [Syncopal neuralgia of the glossopharyngeal nerve caused by tumoral invasiveness. Therapeutic management. Apropos of 2 cases.] Rev Laryngol Otol Rhinol (Bord) 117:137-140, 1996 (Fr)

2. Chen J, Sindou M: Vago-glossopharyngeal neuralgia: a literature review of neurosurgical experience. Acta Neurochir (Wien) 157:311-321, 2015

3. Dalessio DJ: Diagnosis and treatment of cranial neuralgias. Med Clin North Am 75:605-615, 1991

4. Dhople AA, Adams JR, Maggio WW, Naqvi SA, Regine WF, Kwok Y: Long-term outcomes of Gamma Knife radiosurgery for classic trigeminal neuralgia: implications of treatment and critical review of the literature. Clinical article. J Neurosurg 111:351-358, 2009

5. Ferroli P, Fioravanti A, Schiariti M, Tringali G, Franzini A, Calbucci F, et al: Microvascular decompression for glossopharyngeal neuralgia: a long-term retrospectic review of the Milan-Bologna experience in 31 consecutive cases. Acta Neurochir (Wien) 151:1245-1250, 2009

6. Gadient PM, Smith JH: The neuralgias: diagnosis and management. Curr Neurol Neurosci Rep 14:459, 2014

7. Haller S, Etienne L, Kövari E, Varoquaux AD, Urbach H, Becker M: Imaging of neurovascular compression syndromes: trigeminal neuralgia, hemifacial spasm, vestibular paroxysmia, and glossopharyngeal neuralgia. AJNR Am J Neuroradiol 37:1384-1392, 2016

8. Hamada O, Ogata T, Abe H, Okawa M, Higashi T, Matsumoto J, et al: [A patient with vertebral artery dissection who initially suffered from pharyngeal pain.] No Shinkei Geka 41:1081-1085, 2013 (Jpn)

9. Harris W: Persistent pain in lesions of the peripheral and central nervous system. BMJ 2:896-900, 1921

10. Hayashi M, Ochiai T, Nakaya K, Chernov M, Tamura N, Maruyama T, et al: Current treatment strategy for vestibular schwannoma: image-guided robotic microradiosurgery. J Neurosurg 105 Suppl:5-11, 2006

11. Hayashi M, Ochiai T, Nakaya K, Chernov M, Tamura N, Yomo S, et al: Image-guided microradiosurgery for skull base tumors: advantages of using gadolinium-enhanced constructive interference in steady-state imaging. J Neurosurg 105 Suppl:12-17, 2006

12. Headache Classification Committee of the International Headache Society (IHS): The International Classification of Headache Disorders, 3rd edition (beta version). Cephalalgia Int J Headache 33:629-808, 2013

13. Héroux F, Mathieu D: Treatment of glossopharyngeal neu- ralgia by Gamma Knife radiosurgery. Can J Neurol Sci 42:350-352, 2015

14. Katusic S, Williams DB, Beard CM, Bergstralh E, Kurland LT: Incidence and clinical features of glossopharyngeal neuralgia, Rochester, Minnesota, 1945-1984. Neuroepidemiology 10:266-275, 1991

15. Kondo A: Follow-up results of using microvascular decompression for treatment of glossopharyngeal neuralgia. J Neurosurg 88:221-225, 1998

16. Kondziolka D, Zorro O, Lobato-Polo J, Kano H, Flannery TJ, Flickinger JC, et al: Gamma Knife stereotactic radiosurgery for idiopathic trigeminal neuralgia. J Neurosurg 112:758765,2010

17. Laha RK, Jannetta PJ: Glossopharyngeal neuralgia. J Neurosurg 47:316-320, 1977

18. Lazorthes Y, Verdie JC: Radiofrequency coagulation of the petrous ganglion in glossopharyngeal neuralgia. Neurosurgery 4:512-516, 1979

19. Lazorthes Y, Verdie JC: [Treatment using percutaneous thermocoagulation of trigeminal and glossopharyngeal neuralgias.] Bull Group Int Rech Sci Stomatol Odontol 20:297-309, 1977 (Fr)

20. Lévêque M, Park MC, Melhaoul A, Yomo S, Donnet A, Régis J: Gamma Knife radiosurgery for glossopharyngeal neuralgia, Marseille: experience. J Radiosurg SBRT 1:41-46, 2011

21. Ma Y, Li Y, Wang Q, Wang B, Huang H: Neurosurgical treatment of glossopharyngeal neuralgia: analysis of 103 cases. J Neurosurg 124:1088-1092, 2016

22. Martínez-Âlvarez R, Martínez-Moreno N, Kusak ME, ReyPortolés G: Glossopharyngeal neuralgia and radiosurgery. J Neurosurg 121 Suppl:222-225, 2014

23. Massager N, Murata N, Tamura M, Devriendt D, Levivier M, Régis J: Influence of nerve radiation dose in the incidence of trigeminal dysfunction after trigeminal neuralgia radiosurgery. Neurosurgery 60:681-688, 2007

24. O'Connor JK, Bidiwala S: Effectiveness and safety of Gamma Knife radiosurgery for glossopharyngeal neuralgia. Proc Bayl Univ Med Cent 26:262-264, 2013

25. Patel A, Kassam A, Horowitz M, Chang YF: Microvascular decompression in the management of glossopharyngeal neuralgia: analysis of 217 cases. Neurosurgery 50:705-711, 2002

26. Pollock BE, Boes CJ: Stereotactic radiosurgery for glossopharyngeal neuralgia: preliminary report of 5 cases. J Neurosurg 115:936-939, 2011

27. Régis J, Tuleasca C, Resseguier N, Carron R, Donnet A, Gaudart J, et al: Long-term safety and efficacy of Gamma Knife surgery in classical trigeminal neuralgia: a 497-patient historical cohort study. J Neurosurg 124:1079-1087, 2016

28. Régis J, Tuleasca C, Resseguier N, Carron R, Donnet A, Yomo $\mathrm{S}$, et al: The very long-term outcome of radiosurgery for classical trigeminal neuralgia. Stereotact Funct Neurosurg 94:24-32, 2016

29. Rey-Dios R, Cohen-Gadol AA: Current neurosurgical management of glossopharyngeal neuralgia and technical nuances for microvascular decompression surgery. Neurosurg Focus 34(3):E8, 2013

30. Rogers CL, Shetter AG, Fiedler JA, Smith KA, Han PP, Speiser BL: Gamma Knife radiosurgery for trigeminal neuralgia: the initial experience of the Barrow Neurological Institute. Int J Radiat Oncol Biol Phys 47:1013-1019, 2000

31. Rozen TD: Trigeminal neuralgia and glossopharyngeal neuralgia. Neurol Clin 22:185-206, 2004

32. Rushton JG, Stevens JC, Miller RH: Glossopharyngeal (vagoglossopharyngeal) neuralgia: a study of 217 cases. Arch Neurol 38:201-205, 1981

33. Sampson JH, Grossi PM, Asaoka K, Fukushima T: Microvascular decompression for glossopharyngeal neuralgia: 
long-term effectiveness and complication avoidance. Neurosurgery 54:884-890, 2004

34. Sindou M, Keravel Y: [Neurosurgical treatment of vago-glossopharyngeal neuralgia.] Neurochirurgie 55:231-235, 2009 (Fr)

35. Stanic S, Franklin SD, Pappas CT, Stern RL: Gamma Knife radiosurgery for recurrent glossopharyngeal neuralgia after microvascular decompression. Stereotact Funct Neurosurg 90:188-191, 2012

36. Stieber VW, Bourland JD, Ellis TL: Glossopharyngeal neuralgia treated with Gamma Knife surgery: treatment outcome and failure analysis. Case report. J Neurosurg 102 Suppl:155-157, 2005

37. Tanrikulu L, Hastreiter P, Dörfler A, Buchfelder M, Naraghi $\mathrm{R}$ : Classification of neurovascular compression in glossopharyngeal neuralgia: Three-dimensional visualization of the glossopharyngeal nerve. Surg Neurol Int 6:189, 2015

38. Tuleasca C, Carron R, Resseguier N, Donnet A, Roussel P, Gaudart J, et al: Decreased probability of initial pain cessation in classic trigeminal neuralgia treated with Gamma Knife surgery in case of previous microvascular decompression: a prospective series of 45 patients with $>1$ year of follow-up. Neurosurgery 77:87-95, 2015

39. Williams BJ, Schlesinger D, Sheehan J: Glossopharyngeal neuralgia treated with Gamma Knife radiosurgery. World Neurosurg 73:413-417, 2010
40. Xiong NX, Tan D, Fu P, Zhao HY: Gamma Knife radiosurgery for glossopharyngeal neuralgia by targeting the medial cisternal segment of the glossopharyngeal nerve: report of 3 cases. Stereotact Funct Neurosurg 93:292-296, 2015

41. Yomo S, Arkha Y, Donnet A, Régis J: Gamma Knife surgery for glossopharyngeal neuralgia. J Neurosurg 110:559-563, 2009

\section{Disclosures}

The authors report no conflict of interest concerning the materials or methods used in this study or the findings specified in this paper.

\section{Author Contributions}

Conception and design: Pommier, Blond. Acquisition of data: all authors. Analysis and interpretation of data: Pommier. Drafting the article: Pommier. Critically revising the article: Blond, Reyns Administrative/technical/material support: Vermandel, Blond, Reyns. Study supervision: Touzet, Blond, Reyns.

\section{Correspondence}

Benjamin Pommier, Service de Neurochirurgie, Hôpital nord - F-42055 Saint-Etienne Cedex 2, France. email: benjamin. pommier@neurochirurgie.fr. 